\title{
A mixed method evaluation of cooperative learning using jigsaw classroom model in clinical pharmacology course
}

Uzma ASIF ( $\square$ uzma.aasif1@gmail.com )

Batterjee Medical College for Science and Technology, Jeddah, KSA

Nusrat Bano

King Saud bin Abdulaziz University for Health Sciences

Neelam Malick

Iqra University

Shakeel Ahmed Ansari

Batterjee Medical College for Science and Technology, Jeddah, KSA

\section{Research Article}

Keywords: cooperative, learning, jigsaw, pharmacology

Posted Date: November 1st, 2021

DOI: https://doi.org/10.21203/rs.3.rs-1036508/v1

License: (9) This work is licensed under a Creative Commons Attribution 4.0 International License. Read Full License 


\section{Abstract \\ Purpose}

To evaluate use of cooperative learning using jigsaw classroom model in clinical pharmacology course for undergraduate university students.

\section{Methods}

A sequential mixed method study design was used. Jigsaw learning was used for teaching selected topics in clinical pharmacology course in addition to traditional lectures used to conduct the remaining topics. At the end of the course, students completed the Jigsaw learning assessment instrument that measured attitude, knowledge, skills and satisfaction. In-depth interviews were conducted to explore their experiences. Test scores of teaching content taught by Jigsaw learning was compared to the content delivered by traditional lectures.

\section{Results}

Lowest mean score depicting strongly positive response were observed for survey item-3 (1.9 \pm 0.98$)$, item$13(1.9 \pm 0.88)$ and item-19 $(1.8 \pm 0.86)$ within the subscales measuring attitude, skills and satisfaction respectively. Difference between the test performance in course content delivered by jigsaw classroom technique compared to traditional lectures was statistically significant $(p<0.001)$. Difference between mean responses of high and low test scoring students was significant for survey item- $4(p=0.04)$, item- 8 $(p=0.001)$, item-11, $12(p=0.01,0.02)$ and item-16 $(p=0.03)$.

\section{Conclusion}

Jigsaw classroom model had positive effects on the attitude, knowledge, skills, satisfaction and test performance of students in clinical pharmacology course.

\section{Introduction}

Cooperative learning classroom techniques are based on completion of the learning tasks in small groups. The students in a cooperative learning classroom are recognized or rewarded on their group performances. Cooperative learning classroom techniques improve academic achievement, team work skills, student self-esteem and yield positive learning outcomes. ${ }^{1}$ The theoretical underpinnings of cooperative learning lie in social constructivism proposed by Lev Semyonovich Vygotsky (1896-1934), who proposed that assistance by more skilled persons e.g. peers/teachers, changes the support level of the learners and enables them to advance in their zones of proximal development. ${ }^{2}$ To understand the 
ties between Jigsaw learning and zone of proximal development, it is important to note that Jigsaw classroom model is based on the principles of cooperative learning. The zone of proximal development and cooperative learning can be effectively used to enable and assist learners through the disequilibrium processes. It facilitates assimilation and accommodation of new information and skills into the learner's own practice. ${ }^{3}$ Disequilibrium in Piaget's theory is the period of perplexity that may arise due to inequalities in interpersonal exchange. ${ }^{4}$ Furthermore, in social constructivism, the peers/teachers also adjust support levels in order to adapt to the needs of the learner during the course of study, which is a process known as scaffolding. Scaffolding necessitates that assessment is made on existing understanding of the learner by the teacher, before lending support. ${ }^{5}$ The process of assessment allows the teacher to adjust the amount of support required by the learner. In the scaffolding process, the rendered support lies within a learner's zone of proximal development. ${ }^{6}$ In Vygotsky's theory of social constructivism, social interaction is the key to learning available knowledge without a need to reinvent concepts. ${ }^{2,7-8}$

There are several cooperative learning techniques such as peer instruction, inter teaching and jigsaw classroom. Peer instruction and inter teaching are seen as 'clearly effective strategies' that improve student performance but do not require the learners to be interdependent, unlike jigsaw classroom. ${ }^{9}$

The jigsaw classroom model is categorized as the type of cooperative learning technique that involves task specialization and individual rewards. ${ }^{10}$ Decades of research revealed that implementation of the jigsaw classroom reduces student's prejudice, which is its primary goal.$^{9}$ The jigsaw classroom learning technique fosters feelings of competence in learners and enhances their intrinsic motivation. ${ }^{11}$

The jigsaw classroom learning model was first used by Elliot Aronson ${ }^{12,13}$. It comprises of four stages. In the introduction (first) phase, the class is divided by formation of small heterogeneous groups (3-7 members), also known as 'home groups'. In the exploration (second) phase, each member of the home group is assigned to a specific learning task. The students assigned to the same learning task come together as 'expert group' and explore the learning content within an assigned time frame. This enables task specialization in the students. ${ }^{9}$ This is followed by the reporting and reshaping (third) phase, which require students to rejoin their home groups and share their learning with the rest of the members in the home group one by one. This learning activity is also time bound and monitored by the facilitator. In the integration and evaluation (final) phase, the acquired knowledge is assessed. ${ }^{12,13}$ The students get individual rewards immediately when they are quizzed and their knowledge is assessed. ${ }^{9}$ Jigsaw learning model is effectively used in higher education and improves academic motivation and selfregulated learning. ${ }^{14}$ Jigsaw learning model is frequently used in undergraduate university students. It potentiates high order social and cognitive learning in undergraduate students. ${ }^{15}$ Studies in university students have also shown that students in jigsaw learning group were comparatively more successful than students in non-jigsaw learning group. ${ }^{16}$ 
Traditional teaching method comprising of didactic lectures and unstructured group assignments are generally used in clinical pharmacology course. Course feedback survey reports show that students completing the clinical pharmacology course find it lengthy and complex. The jigsaw classroom is a learner's centered instructional design based on structured group work. Structured group work fosters teamwork skills ensuring individual accountability and is more beneficial than unstructured group work that leads to decreased motivation and negative interpersonal effects i.e. social loafing. ${ }^{17-19}$ Owing to this, cooperative learning is usually received well by students in difficult and technical courses. ${ }^{20,21}$ The usual challenge in a clinical pharmacology course is to improve test performance and effectively develop disease management skills with appropriate use of medications. ${ }^{22,23}$ Nolan et al (2018) showed that the jigsaw learning method imparts positive effects on both short and long term memory recall in tests, while the students are able to grasp the concepts more readily with effective thought organization skills attained in jigsaw classrooms. ${ }^{9}$ This classroom technique is also reported to be effective in improving the technical and non-technical disease management skills (e.g. cardiac arrest) as well as the test scores in internal medicine residents. ${ }^{24}$

Thus we posit that the jigsaw classroom technique used in a clinical pharmacology course will positively affect the learning experience and academic performance of the students. The purpose of this study was to evaluate the effects of the jigsaw classroom learning on the attitude, knowledge, skills, satisfaction and test performance of undergraduate health science students enrolled in a clinical pharmacology course.

\section{Methods}

\subsection{Overview}

This study was a mixed method observational study and had a sequential design. ${ }^{25}$ The mixed method study design allows integration of qualitative and quantitative data and thus provides a better understanding and corroboration. In this study, the qualitative data was collected after completion of the quantitative data collection. During the interpretation and analysis of the results, the two methods were fully integrated following guidelines on mixed methods research. ${ }^{26,27}$ The outcomes of the qualitative and quantitative data sets were compared and contrasted. Implications and inferences of this study are thus informed by this integration.

\subsection{Participants}

Study sample comprised of health science students, enrolled in the three credit hours clinical pharmacology course. All students were in the second year of their professional degree program at King Saud Bin Abdulaziz University for Health Sciences. All the students were female and the mean age of the participants in years was $21.23 \pm 1.56$ (mean+ standard deviation). The students were accustomed to traditional didactic lectures and had no previous experience with jigsaw classroom learning.

\subsection{Material and Procedure}




\subsubsection{Instructional design}

The clinical pharmacology course comprised of fifteen main topics, covered over a time period of fifteen weeks. The three (3) class contact hours per week were divided to allow two contact hours for traditional lectures and one contact hour for the jigsaw learning activity. The jigsaw classroom model proposed by Elliot Aronson ${ }^{12,13}$ was used. The whole class was divided in two equal sections by a computer generated enrollment program through the academic office before the course started. Same content was taught across the two sections by a single instructor. For the jigsaw activity in each section, it was further divided into eleven home groups comprising of four students in each group. The permanent home groups were formed based on their enrollment list and posted on the blackboard. Every second member of the group was assigned as group leaders. Each home group member was allocated to a specific learning material uploaded on the blackboard (online learning system), accessible to them on their tablets and smartphones. The learning material was prepared by the course instructor and contained clear information in bullet point format with text book references. The learning material was uploaded 48 hours before the class time and made available to the students.

In the jigsaw classroom, the students allocated to the same learning material comprised 'expert groups'. Members in the expert group discussed the main learning points and refined a presentation plan within 25-30 minutes of class time. Every member of the home group was a part of a separate expert group. The expert group members returned to their home groups and shared acquired information with the rest of the members of in their home group. The instructor facilitated the activity by observing the process, prompting discussion and rendering support to the learners. The instructor was vigilant, mobile and approached each group during the activity. Constant assessment of learner's need was made employing

diagnostic strategies ${ }^{5}$ e.g. why a learner is struggling during explanation or listening?. The instructor also asked questions when required as intervention strategy.

A four to five item oral quiz competition was conducted at the end of the class to allow for an instant reward system. The class concluded with the announcement of 'best home group for the week', comprising of members with the highest number of accurate responses. Figure 1 illustrates an example of jigsaw classroom activity and group formation for a large group of students.

(Insert Figure one here)

\subsubsection{Data collection}

This study had a sequential research design. Qualitative data collection was initiated after quantitative data elicitation. Quantitative data collection ensued in two parts, following the completion of the course. In the first part, effectiveness of the jigsaw classroom on test performance of the students was assessed. 
All the students enrolled in the course undertook a test which comprising of $60 \mathrm{MCQ}$ items. Among the 60 $M C Q$, the first 30 MCQ assessed learning of the content taught in the Jigsaw classroom whereas, the last $30 \mathrm{MCQ}$ items assessed content delivered by traditional lectures. Optical mark recognition sheets filled by the students during the test were analyzed.

In the second part of the quantitative data analysis, all the students who had completed the course were invited to fill a questionnaire. The questionnaire was adapted from a jigsaw survey tool developed by Leyva-Mora \& Camps (2016) ${ }^{28}$ and modified to meet the requirements of the clinical pharmacology course. Before administration, the questionnaire was given to three subject experts and their suggestions were incorporated for face validity. It comprised of nineteen statements which were worded positively and measured attitude ( 4 items), knowledge ( 5 items), skills ( 5 items) and satisfaction ( 5 items). It was a 5 point Likert type scale ( $1=$ strongly agree, $2=$ agree, $3=$ neutral, $4=$ disagree and $5=$ strongly disagree). The questionnaire was pretested for reliability in 30 students and had good internal consistency (Cronbach's alpha value of 0.883 ). Each student signed an informed consent form before filling the questionnaire.

After the conclusion of quantitative data collection, qualitative data collection was made. A convenient sample was recruited to participate in in-depth interviews that lasted for an average of 35 minutes. The interviews were (audio) recorded. The probes in the interview were aimed towards elaboration and argumentation of the initial response and meanings (multi layered) that contextualized the responses obtained through the quantitative survey.

\subsection{Analysis}

For the quantitative data analysis, descriptive statistical analysis was conducted on IBM software SPSS version 21.0. The Kolmogorov-Smirnov test showed a normal distribution of the data. Quantitative data collected in part 1 comprised scores of the students in the test which consisted of 60-MCQ items. Half of the test items (30/60) assessed learning in the jigsaw classroom whereas the other half measured learning in traditional classroom. The test scores of the students in course content delivered by jigsaw classroom was compared with the test scores of the students in course content delivered by traditional classroom, using paired sample $t$ test. $p$ value less than 0.05 was considered statistically significant.

Based on test scores, students were categorized into Group A and B for data analysis purposes. Students who scored more than $80 \%$ in this $60-\mathrm{MCQ}$ items test were included in group A whereas the students scoring below $80 \%$ were included in group B. Quantitative data collected in part 2 comprised of responses of the students in the 19-item questionnaire based survey. The responses of Group A were compared with Group B. Independent sample $t$ test was used to compare the variables and $p$ value less than 0.05 was considered statistically significant.

For the qualitative data analysis, a skilled transcriber performed simple verbatim transcription of the audio recorded interviews. Accuracy of the transcribed interviews was cross-checked by careful comparison with the audio recordings by the researchers. The six phase qualitative data analysis approach proposed by Braun and Clarke (2006) ${ }^{29}$ was used for the thematic analysis of the data. The 
interview transcripts were read and re-read for familiarization. Initial codes (inductive) were generated following the active, analytical and critical reading phase. Deductive codes from the survey headings were also used for categorization. Themes and sub themes were generated by active searching of areas with overlaps and similarities. The codes were clustered and collapsed in the process to yield a meaningful and coherent pattern. Potential themes were reviewed critically and also within the context of the whole data, following which they were defined, named and produced. Illustrative quotes were selected on grounds of being most relevant to the theme as well as on the brevity and quality of how they were articulated by the participants.

\section{Results}

The total number of students registered in clinical pharmacology course was eighty seven. Out of the total number, seventy six agreed to participate in the survey, which accounted for approximately $87 \%$ response rate. In the qualitative phase, saturation was attained after seven interviews.

(Insert Table one here)

\subsection{Jigsaw learning assessment}

Table 1 shows the mean and standard deviation for each item in Jigsaw learning assessment scale based on student's response. The average value of the overall score on the Jigsaw learning assessment scale (mean=2.12, SD=1.042) was lower than the mean value (3) of the five point Likert scale.

3.1.1 Attitude: Among the four subscales of Jigsaw learning assessment tool, the lowest overall score (most positive response) was for the subscale measuring attitude towards Jigsaw learning (mean=2.07, $\mathrm{SD}=1.02)$. This was further supported by interview narratives:

'Maybe after three weeks, I started to feel something new about myself. I found out that I can actually help someone learn difficult things about drugs. I met the teacher inside me for the first time. I started feeling positive about this class activity after that.'(Alice)

I was getting better in learning alone and also with others, sometimes it was interesting to see how others used funny ways to remember drug names, but you know it really works. It is much better than listening to lectures by just sitting in the class.'(Rosalie)

For the survey item-3, that measured student's attitude towards teamwork, highly positive response (mean=1.9, SD=0.98) was noted with the subscale that measured attitude. It was elaborated in the interviews: 
'I never talked to some girls in the class, but when we were together in the expert group; we started talking and helped each other learn. Even afterwards, we sat together, talking about how different things happened when we explained the same things to the home group. We also exchanged ideas on what worked well and what did not. It helped us learn better next time.'(Jessica)

3.1.2 Knowledge: The overall mean score for the subscale measuring knowledge was $2.14 \pm 1.06$, which was lower than the mean value (3) of the five point Likert scale. Within the subscale that measured knowledge, lowest score (mean=2.0, SD =1.11) was for the survey item-9 (Jigsaw Technique has helped me to understand the examples of drug interaction). During the interviews, this notion was supported:

'The teacher asked each one of us in the expert group to discusses 'drug to drug' and 'drug to food' interactions, but we were told to search online for different examples. It was like a competition for us because of time limit. But then, we also looked at each other's examples, and there was a lot of discussion on which was the best to share with the home group. I still remember many examples. It helped me solve the case studies in the exam.'(Karen)

3.1.3 Skills: The overall score for the subscale measuring skills was lower than the mean value (3) of the five point Likert scale (mean=2.12, $S D=1.01$ ). The lowest score (mean=1.9, $S D=0.88$ ) was for survey item 13- (Jigsaw Technique has helped me develop patient education skills). This was stated more saliently as a positive aspect of jigsaw learning, during the interviews:

'whenever someone asked us about patient education before drug administration, the toughest part for all of us was to decide, what information to give and what can be left out, .... Now we can select the most important and practical things about drugs in a short time, because we practiced teaching so many times with the home group'. (Alice)

'In my home group, some girls asked so many questions and some just listened and did not say anything. I was confused if they even understood me. But after how they did in pop quiz, I got confident. I know, how to give information about drugs now, I know, I can use it for patient education.'(Amber)

3.1.4 Satisfaction: The overall score for the subscale measuring knowledge was lower than the mean value of the questionnaire scale (mean $=2.14, S D=1.06$ ). In response to interview questions regarding overall satisfaction with jigsaw learning, the students said that:

'I was not happy in the beginning, it was new for us, but after few classes, we started feeling that the information is sticking in our brains, it helped us in our tests, we are very happy with it now.'(Jessica)

'Some girls did not teach us in a good way, and they were not happy when we told them that we lost in pop quiz because they never gave us the complete information.'(Karen)

The most positive response within the subscale measuring overall satisfaction was for survey item- 19 , with a low score (mean=1.8, SD=0.86). Within the same subscale, low positive satisfaction was noted for 
survey item-16 (mean=2.3, SD=1.07) and survey item-17(mean=2.4, SD=1.11). During the interviews similar narratives were as follows:

'Some girls did not download everything from the blackboard. And they were not prepared to teach us in the home group.'(Karen)

'I think that information on the blackboard should be in points only, because we do not have much time when we reviewing it in the expert group.' (Amber)

'I do not think it should be done in all courses because teachers need to explain, they know many things that we cannot learn ourselves. The time for us to learn is also little and we had to go teach in home group. For pharmacology we have the same format for drug profile, you know, MOA, dose, route, adverse effects etc.' (Angela)

'For me, it depends on the teacher who is doing the course, you know sometimes the course is tough and teacher says you should have that information because you already studied it last year, so it is better to have only lectures from them.'(Rosalie)

\subsection{Difference between questionnaire responses of group $A$ and Group $B$}

Table 2 shows the responses of the students to the questionnaire items. It illustrates the difference between group $A$ and group $B$.

(Insert Table two here)

The difference between the two groups of students was significant for survey item- $4(p=0.04)$ and item- 8 $(p=0.001)$ within the subscales of attitude and knowledge respectively. There was statistically significant difference between the two groups of students for survey item-12 ( $p=0.01)$ and survey item-13 $(p=0.02)$, which were related to subscale measuring skills. For the survey item-16, within the subscale that measured student's satisfaction, the difference in the mean scores between the two groups was statistically significant $(p=0.03)$.

\subsection{Comparative test scores between jigsaw and traditional classrooms}

Total possible score in the 60 -items MCQ based test was 60 . The mean score \pm standard deviation was 45.38 \pm 7.60. Reliability coefficient (Kuder-Richardson Formula 20) was 0.86.

Difference in the mean percentile scores for course content delivered in jigsaw classroom compared to course content delivered in traditional classroom is shown in Table 2. The difference between the total 
scores is highly significant $(p<0.001)$.

(Insert Table three here)

\section{Discussion}

This study was designed to assess effects of a cooperative learning module using jigsaw classroom on university student's attitude, knowledge, skills, test performance and overall satisfaction in clinical pharmacology course.

Student's responses to the questionnaire indicate that jigsaw classroom helped them develop a critical approach towards learning and complete learning tasks within a given time frame. This finding is supported in earlier studies showing that jigsaw classroom model improved critical thinking skills regarding drug information. ${ }^{30}$ In the present study, the students mentioned a gradual thawing process towards the new learning technique as they began to discover their own personal talents e.g. teaching peers, interpersonal skills, effective social interaction. The students expressed that the jigsaw classroom helped them to overcome certain social barriers and reach out to one another. In the same breath, it was noted that the students considered the jigsaw classroom technique to be more useful for group learning rather than individual learning. Similar observations were made by Depaz \& Moni $(2008)^{31}$, who reported that majority of their pharmacology course students enjoyed group work in the jigsaw classroom.

Most of the students in the present study agreed that the jigsaw technique helped them gain knowledge of core concepts in pharmacology. It provided them with an opportunity to observe different learning methods used by peers and adapt accordingly. These findings suggest that the techniques within the paradigm of cooperative learning, enhance deep learning in difficult and complex courses in higher education. ${ }^{32}$

Student's responses to the questionnaire also show that the activities in the jigsaw classroom helped the students in developing dose calculation, adverse drug monitoring and in particular patient education skills. This is particularly interesting because one of the biggest challenges encountered by health science students is to effectively translate theoretical pharmacological knowledge into practically useful application skills in clinical settings. ${ }^{33,34}$

Overall satisfaction in the jigsaw classroom was good and many students favoured the continuation of this technique. There was a significant difference $(p=0.04)$ in student's attitude towards time constraints in jigsaw classroom. Students in group $A$ had a more positive response (mean=1.9; $S D=0.95$ ) compared to Group $B$ (mean=2.4; $S D=1.0$ ). This finding suggests that by assigning realistic and feasible time frames to the learning tasks, a more homogenous effect on test performance of the students can be 
expected. A marked difference between the two groups of students was noted regarding effects of the jigsaw learning technique on pharmacodynamics concepts. Students in Group A were more positive that the jigsaw classroom technique improved learning of the pharmacodynamics processes. It has been previously shown that students grasp concepts in pharmacodynamics more readily than pharmacokinetics and drug interactions. ${ }^{35}$ This study however, shows that the group of students scoring high in pharmacology test, have a more positive perception of the utility of jigsaw classroom technique in learning pharmacodynamics.

Some of the students did not agree that the online learning resource generated for this course was very helpful. During the interviews, it was often noted that the students preferred a more concise set of information that could be easily studied for their expert group activity. In terms of accountability and responsibilities, students were critical about the quality of information received from their peers. Students showed concern about the reception of the knowledge that was exchanged among peers. Classroom interactions between different types of students (e.g. gifted, mixed ability etc.) in cooperative learning

have long enticed instructors and researchers in pursuit of the optimal combination within a group. ${ }^{36}$

As shown in Table 3, students performed better in the test items pertaining to the content delivered in the jigsaw classroom compared to the content delivered by traditional lectures. Low pass rates and poor test performances are often observed in pharmacology courses ${ }^{37,38}$ however, this study shows that the jigsaw classroom model can be effectively used by pharmacology instructors aspiring to improve the test performances in their students. It has been noticed that active-learning techniques is significantly advantageous for interdisciplinary sciences ${ }^{39}$. In terms of health professional education, several studies have been reported to enhance the significant addition of jigsaw teaching methodologies to motivate students' critical thinking, motivational participation, engagement and learning outcome in various countries. ${ }^{40,41}$

\subsection{Study limitations}

This study has some limitations. It reports finding from a single institute. The sample size is small and all study participants were female. Long term effects of jigsaw learning technique on retention of knowledge were not addressed. Future research within a longitudinal frame and data source triangulation is suggested.

\section{Conclusion}

Jigsaw classroom model had positive effects on the attitude, knowledge, skills, and satisfaction of students in clinical pharmacology course. Student's test performance in course content delivered in the jigsaw classroom was better than traditional classroom. The cooperative learning model helped the students in development of patient education skills.

\section{Declarations}




\section{Disclosure statement:}

No potential conflict of interest is reported by the authors

\section{References}

1. Slavin RE. Cooperative learning. Rev Educ Res. 1980; 50:315-42.

2. Vygotsky L. Interaction between learning and development. In: Vygotsky, L, Mind in Society. Cambridge, MA: Harvard University Press; 1978: 79-91.

3. Clapper TC. Cooperative-based learning and the zone of proximal development. Simulation \& Gaming. 2015 Apr; 46(2):148-58.

4. Poplin MS. Holistic/constructivist principles of the teaching/learning process: Implications for the field of learning disabilities. Journal of learning Disabilities. 1988 Aug;21(7):401-16.

5. Van de Pol J, Volman M, Beishuizen J. Promoting teacher scaffolding in small-group work: A contingency perspective. Teaching and Teacher Education. 2012 Feb 1;28(2):193-205.

6. Roehler LR, Cantlon DJ. Scaffolding: A powerful tool in social constructivist classrooms. Scaffolding student learning: Instructional approaches and issues. 1997;1:17-30.

7. Slavin RE. Cooperative learning: Theory, research, and practice. Needham Heights, MA: Simon \& Schuster Company; 1995.

8. Slavin RE. Instruction based on cooperative learning. In R. Mayer (Ed.), Handbook of research on learning and instruction. London: Taylor \& Francis; 2011.

9. Nolan JM, Hanley BG, DiVietri TP, Harvey NA. She who teaches learns: Performance benefits of a jigsaw activity in a college classroom. Scholarship of Teaching and Learning in Psychology. 2018 Jun;4(2):93.

10. Slavin RE. When does cooperative learning increase student achievement?. Psychological bulletin. 1983 Nov;94(3):429.

11. Hänze M, Berger R. Cooperative learning, motivational effects, and student characteristics: An experimental study comparing cooperative learning and direct instruction in 12th grade physics classes. Learning and instruction. 2007 Feb 1;17(1):29-41.

12. Aronson E, Patnoe S. Cooperation in the classroom: The jigsaw method (3rd ed.). London, England: Printer \& Martin Limited; 2011.

13. Aronson, E, Blaney N, Stephin C, Sikes J. The jigsaw classroom. Beverly Hills, CA: Sage Publishing; 1978.

14. Sanaie N, Vasli P, Sedighi L, Sadeghi B. Comparing the effect of lecture and Jigsaw teaching strategies on the nursing students' self-regulated learning and academic motivation: A quasiexperimental study. Nurse Educ Today. 2019; 79:35-40.-15

15. O'Leary N, Barber A, Keane H. Physical education undergraduate students' perceptions of their learning using the jigsaw learning method. European Physical Education Review. 2019 Aug; 
25(3):713-30.

16. Doymus K. Teaching chemical bonding through jigsaw cooperative learning. Research in Science \& Technological Education. 2008 Apr 1;26(1):47-57.

17. Ying X, Li H, Jiang S, Peng F, Lin Z. Group laziness: The effect of social loafing on group performance. Soc Behav Pers. 2014; 42 (3): 465-471. doi: 10.2224/sbp.2014.42.3.46

18. Meyer B., Schermuly C, Kauffeld S. That's not my place: The interacting effects of faultlines, subgroup size, and social competence on social loafing behavior in work groups. Eur J Work Organ Psychol. 2016; 25(1): 31-49.

19. Premo J, Cavagnetto A, Davis WB, Brickman P. Promoting collaborative classrooms: the impacts of interdependent cooperative learning on undergraduate interactions and achievement. CBE Life Sci Educ. 2018; 17(2):ar32. doi: 10.1187/cbe.17-08-0176.

20. Felder and R. Brent. Cooperative learning in technical courses: Procedures, pitfalls, and payoffs. ERIC Document Reproduction Service Report ED 377 038; 1994.

21. Elberson KL, Vance AR, Stephenson NL, Corbett RW. Cooperative learning: a strategy for teaching pathophysiology to undergraduate nursing students. Nurse Educ. 2001;26(6):259-61.

22. Alton S. Learning how to learn: Meta-learning strategies for the challenges of learning pharmacology. Nurse Education Today. 2016 Mar 1;38:2-4.

23. Bano N, de Beer J, Omer TY. Team-based learning in postgraduate midwifery education: A descriptive qualitative study. Education in the Health Professions. 2019 Jul 1;2(2):98.

24. Fryman C, Fei A, Mehta R, Ahmad S. Jigsaw method for non-technical skills in cardiac arrest: A novel application of this active learning pedagogy. Medical Science Educator. 2018 Jun 1;28(2):401-5.

25. Padgett DK. Qualitative and mixed methods in public health. Thousand Oaks, CA: Sage publications; 2011.

26. Cameron R. Mixed Methods Research: The Five Ps Framework. Electronic Journal of Business Research Methods. 2011; 9(2):96-108

27. Kroll T, Neri M. Designs for mixed methods research. In: Andrew, S., Halcomb, E.J. (Eds.), Mixed Methods Research for Nursing and the Health Sciences. Wiley-Blackwell, Chichester, 2009; 31-49.

28. Leyva-Moral JM, Camps MR. Teaching research methods in nursing using Aronson's Jigsaw Technique. A cross-sectional survey of student satisfaction. Nurse Educ Today. 2016; 40: 78-83. doi.org/10.1016/j.nedt.2016.02.017

29. Braun V, Clarke V. Using thematic analysis in psychology. Qualitative research in psychology. 2006; 3(2):77-101.

30. Earl GL. Using cooperative learning for a drug information assignment. Am J Pharm Educ. 2009; 73(7):132.

31. Depaz I, Moni RW. Using peer teaching to support co-operative learning in undergraduate pharmacology. Bioscience education. 2008; 11(1): 1-12.-32 
32. Azizan MT, Mellon N, Ramli RM, Yusup S. Improving teamwork skills and enhancing deep learning via development of board game using cooperative learning method in Reaction Engineering course. Educ Chem Eng. 2018; 22: 1-13, 10.1016/J.ECE.2017.10.002-33

33. Nielsen A. Concept-based learning in clinical experiences: Bringing theory to clinical education for deep learning. J Nurs Educ. 2016; 55(7): 365-371.-34

34. Preston P, Leone-Sheehan D, Keys B. Nursing student perceptions of pharmacology education and safe medication administration: A qualitative research study. Nurse Educ Today. 2019; 74: 76-81.

35. Aronsson P, Booth S, Hägg S, Kjellgren K, Zetterqvist A, Tobin G, Reis M. The understanding of core pharmacological concepts among health care students in their final semester. BMC medical education. 2015 Dec;15(1):235.

36. Patrick H, Bangel NJ, Jeon KN, Townsend MA. Reconsidering the issue of cooperative learning with gifted students. Journal for the Education of the Gifted. 2005; 29(1): 90-108.

37. Brandl K, Schneid SD, Tsunoda SM, Awdishu L. A redesigned pharmacology series increases students' satisfaction and is associated with improved performance in therapeutics. Am J Pharm Educ. 2018; 6971. doi/pdf/10.5688/ajpe6971

38. Quinn BL, Smolinski M, Peters AB. Strategies to improve NCLEX-RN success: A Review. Teaching and Learning in Nursing. 2018.; 13(1): 18-26. 10.1016/j.teln.2017.09.002

39. Atallah AA, Hassen MF, Musa AB, Bougherira MR, Frih N. The Application of the Jigsaw Cooperative Learning Technique in Mapping Concepts of Nuclear Radiation in Diagnosis and Therapy. International Journal of Learning, Teaching and Educational Research. 2021 Aug 14;20(7).

40. Karimi Moonaghi H, Bagheri M. Jigsaw: A good student-centered method in medical education. Future of Medical Education Journal. 2017;7(1):35-40.

41. Shakerian S, Khoshgoftar Z, Rezayof E, Amadi M. The Use of the Jigsaw Cooperative Learning Technique for the Health Science Students in Iran: A Meta-Analysis. Educational Research in Medical Sciences. 2020 Jun 30;9(1).

\section{Tables}

Table 1. Student's response to jigsaw learning assessment questionnaire. 


\begin{tabular}{|c|c|c|c|c|}
\hline \multirow[t]{2}{*}{ Item } & \multirow[b]{3}{*}{$\begin{array}{l}\text { Jigsaw technique has helped me to develop a critical attitude towards } \\
\text { learning (a) }\end{array}$} & \multicolumn{3}{|c|}{$\begin{array}{l}\text { Student's } \\
\text { response }\end{array}$} \\
\hline & & \multicolumn{2}{|c|}{ Mean } & \multirow{2}{*}{$\frac{\mathrm{SD}}{1.06}$} \\
\hline Attitudes(a) & & 2.1 & \pm & \\
\hline & Jigsaw technique has helped me to work independently (a) & 2.2 & \pm & 1.06 \\
\hline & Jigsaw technique has helped me to work within a group (a) & 1.9 & \pm & 0.98 \\
\hline & Jigsaw technique has helped me to work within a given time frame(a) & 2.1 & \pm & 1.00 \\
\hline & & 2.07 & \pm & 1.02 \\
\hline \multirow[t]{6}{*}{ knowledge(b) } & $\begin{array}{l}\text { Jigsaw Technique has helped me to understand the knowledge based } \\
\text { course items(b) }\end{array}$ & 2.2 & \pm & 1.15 \\
\hline & $\begin{array}{l}\text { Jigsaw Technique has helped me to understand the application based } \\
\text { course items(b) }\end{array}$ & 2.2 & \pm & 1.05 \\
\hline & $\begin{array}{l}\text { Jigsaw Technique has helped me to understand the aspects of } \\
\text { pharmacokinetic process }(\mathrm{b})\end{array}$ & 2.1 & \pm & 0.96 \\
\hline & $\begin{array}{l}\text { Jigsaw Technique has helped me to understand the aspects of } \\
\text { Pharmacodynamics process }(b)\end{array}$ & 2.2 & \pm & 1.05 \\
\hline & $\begin{array}{l}\text { Jigsaw Technique has helped me to understand the examples of drug } \\
\text { interaction(b) }\end{array}$ & 2.0 & \pm & 1.11 \\
\hline & & 2.14 & \pm & 1.06 \\
\hline \multirow[t]{6}{*}{ Skills (c) } & Jigsaw Technique has helped me develop dose calculation skills(c) & 2.3 & \pm & 1.15 \\
\hline & Jigsaw Technique has helped me develop drug selection skills(c) & 2.3 & \pm & 1.04 \\
\hline & $\begin{array}{l}\text { Jigsaw Technique has helped me develop adverse effect monitoring } \\
\text { skills(c) }\end{array}$ & 2.0 & \pm & 0.93 \\
\hline & Jigsaw Technique has helped me develop patient education skills(c) & 1.9 & \pm & 0.88 \\
\hline & Jigsaw Technique has helped me develop communication skills(c) & 2.1 & \pm & 1.07 \\
\hline & & 2.12 & \pm & 1.01 \\
\hline \multirow[t]{6}{*}{$\begin{array}{l}\text { Satisfaction } \\
\text { (d) }\end{array}$} & $\begin{array}{l}\text { The course assessment has responded to the goals set in the course } \\
\text { specification/syllabus (d) }\end{array}$ & 2.2 & \pm & 1.21 \\
\hline & $\begin{array}{l}\text { Online learning resource (books and learning materials) was a useful } \\
\text { complement to jigsaw technique(d) }\end{array}$ & 2.3 & \pm & 1.07 \\
\hline & $\begin{array}{l}\text { Jigsaw Technique should be applied in other courses, given its } \\
\text { usefulness(d) }\end{array}$ & 2.4 & \pm & 1.11 \\
\hline & Jigsaw Technique should be kept in this course in future years(d) & 2.0 & \pm & 1.07 \\
\hline & Teachers are proficient in conducting Jigsaw Technique groups(d) & 1.8 & \pm & 0.86 \\
\hline & & 2.14 & \pm & 1.06 \\
\hline \multicolumn{2}{|c|}{ Overall survey score } & 2.12 & \pm & 1.042 \\
\hline
\end{tabular}

Table 2. Difference between questionnaire responses of group A and group B. 


\begin{tabular}{|c|c|c|c|c|c|c|}
\hline \multirow[t]{2}{*}{ Item } & & \multicolumn{2}{|c|}{ Group A } & \multicolumn{2}{|c|}{ Group B } & \multirow[t]{2}{*}{$p$} \\
\hline & & Mean & SD & Mean & SD & \\
\hline \multirow[t]{4}{*}{ Attitudes(a) } & $\begin{array}{l}\text { Jigsaw technique has helped me to develop a critical } \\
\text { attitude towards learning (a) }\end{array}$ & 2.0 & .99 & 2.3 & 1.1 & .18 \\
\hline & Jigsaw technique has helped me to work independently (a) & 2.2 & 1.03 & 2.3 & 1.1 & .71 \\
\hline & Jigsaw technique has helped me to work within a group (a) & 1.8 & .79 & 2.1 & 1.2 & .22 \\
\hline & $\begin{array}{l}\text { Jigsaw technique has helped me to work within a given time } \\
\text { frame(a) }\end{array}$ & 1.9 & .95 & 2.4 & 1.0 & .04 \\
\hline \multirow[t]{5}{*}{ knowledge(b) } & $\begin{array}{l}\text { Jigsaw Technique has helped me to understand the } \\
\text { knowledge based course items(b) }\end{array}$ & 2.2 & 1.18 & 2.1 & 1.1 & .91 \\
\hline & $\begin{array}{l}\text { Jigsaw Technique has helped me to understand the } \\
\text { application based course items(b) }\end{array}$ & 2.1 & 1.06 & 2.4 & 1.0 & .18 \\
\hline & $\begin{array}{l}\text { Jigsaw Technique has helped me to understand the aspects } \\
\text { of pharmacokinetic process (b) }\end{array}$ & 1.8 & .96 & 2.4 & 0.9 & .18 \\
\hline & $\begin{array}{l}\text { Jigsaw Technique has helped me to understand the concepts } \\
\text { in Pharmacodynamics (b) }\end{array}$ & 1.9 & .93 & 2.6 & 1.1 & .001 \\
\hline & $\begin{array}{l}\text { Jigsaw Technique has helped me to understand the } \\
\text { examples of drug interaction(b) }\end{array}$ & 1.8 & 1.05 & 2.3 & 1.2 & .07 \\
\hline \multirow[t]{5}{*}{ Skills (c) } & $\begin{array}{l}\text { Jigsaw Technique has helped me develop dose calculation } \\
\text { skills(c) }\end{array}$ & 2.1 & 1.01 & 2.5 & 1.3 & .11 \\
\hline & $\begin{array}{l}\text { Jigsaw Technique has helped me develop drug selection } \\
\text { skills(c) }\end{array}$ & 2.2 & 1.01 & 2.5 & 1.1 & .18 \\
\hline & $\begin{array}{l}\text { Jigsaw Technique has helped me develop adverse effect } \\
\text { monitoring skills(c) }\end{array}$ & 1.8 & .75 & 2.4 & 1.1 & .01 \\
\hline & $\begin{array}{l}\text { Jigsaw Technique has helped me develop patient education } \\
\text { skills(c) }\end{array}$ & 1.7 & .74 & 2.2 & 1.0 & .02 \\
\hline & $\begin{array}{l}\text { Jigsaw Technique has helped me develop communication } \\
\text { skills(c) }\end{array}$ & 2.0 & 1.15 & 2.2 & 0.9 & .39 \\
\hline \multirow[t]{5}{*}{$\begin{array}{l}\text { Satisfaction } \\
\text { (d) }\end{array}$} & $\begin{array}{l}\text { The course assessment has responded to the goals set in } \\
\text { the course specification/syllabus }(d)\end{array}$ & 2.1 & 1.23 & 2.4 & 1.2 & .23 \\
\hline & $\begin{array}{l}\text { Online learning resource (books and learning materials) } \\
\text { was a useful complement to jigsaw technique }(\mathrm{d})\end{array}$ & 2.1 & 1.14 & 2.6 & 0.9 & .03 \\
\hline & $\begin{array}{l}\text { Jigsaw Technique should be applied in other courses, given } \\
\text { its usefulness }(d)\end{array}$ & 2.2 & 1.10 & 2.7 & 1.1 & .06 \\
\hline & $\begin{array}{l}\text { Jigsaw Technique should be kept in this course in future } \\
\text { years }(d)\end{array}$ & 1.9 & .97 & 2.2 & 1.2 & .22 \\
\hline & $\begin{array}{l}\text { Teachers are proficient in conducting Jigsaw Technique } \\
\text { groups }(\mathrm{d})\end{array}$ & 1.7 & .77 & 1.9 & 1.0 & .26 \\
\hline
\end{tabular}

Table 3. Comparison of test scores between jigsaw and traditional classrooms. 


\begin{tabular}{lcccc}
\hline Knowledge and recall items & $88.5 \pm 6.6$ & $76.7 \pm 6.4$ & 4.05 & 0.001 \\
Case analysis items & $90.3 \pm 6.7$ & $54.1 \pm 12.3$ & 11.51 & $<0.001$ \\
Total test score & $89.7 \pm 6.6$ & $61.6 \pm 15.2$ & 9.29 & $<0.001$ \\
\hline
\end{tabular}

\section{Figures}

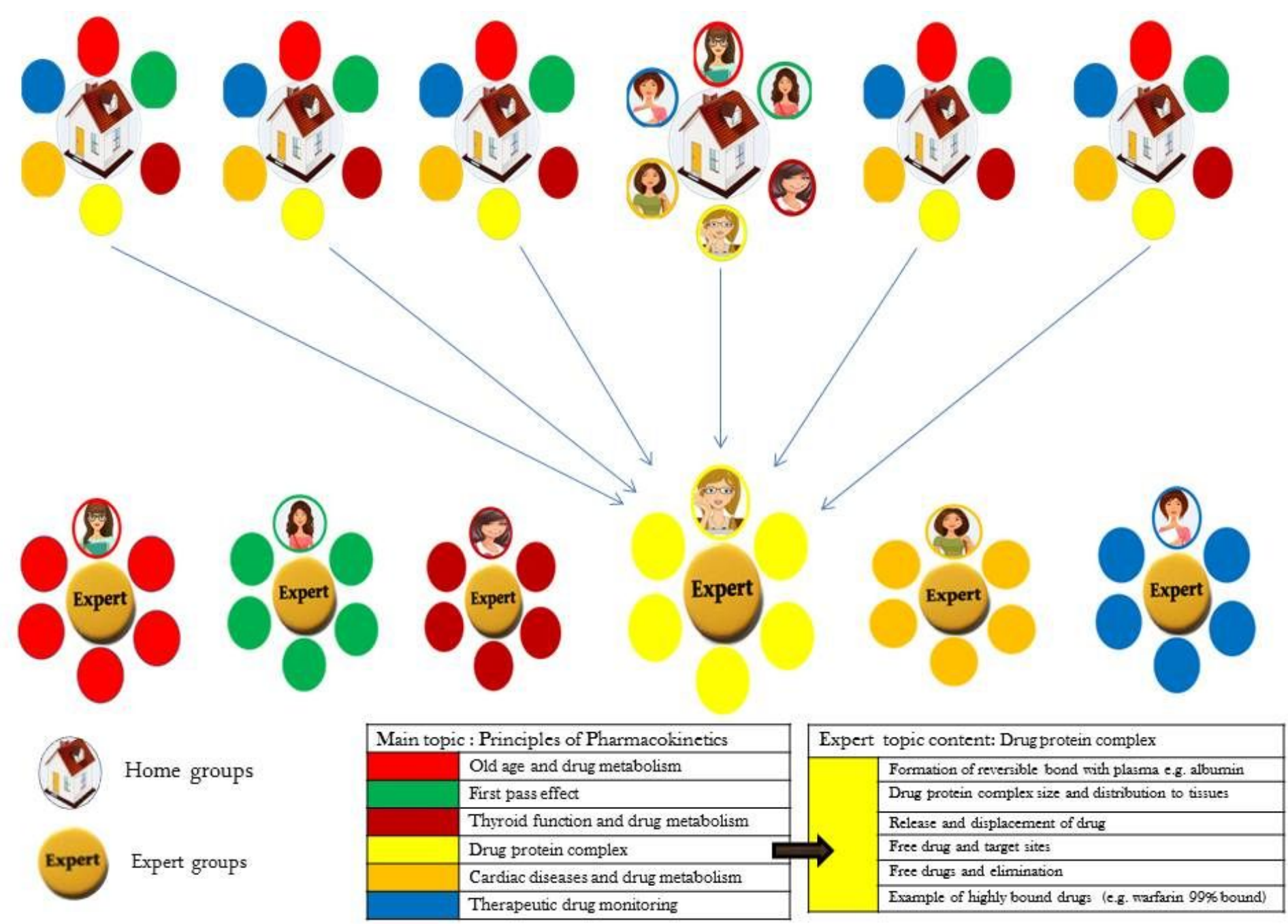

\section{Figure 1}


Example of Jigsaw classroom group formation 